\title{
Formas porosas. Tiempos, movilidad y economías de frontera entre San Pedro de Atacama y Lípez*
}

\author{
Porous Forms. Times, Mobility and Border Economies \\ between San Pedro de Atacama and Lípez
}

\author{
Alejandro Garcés ${ }^{1}$ \\ Universidad Católica del Norte \\ Ignacio González ${ }^{2}$ \\ Pontificia Universidad Católica de Chile \\ Nicolás Richard ${ }^{3}$ \\ CNRS-CREDA \\ Leonardo Soto ${ }^{4}$ \\ Universidad Católica del Norte
}

\section{RESUMEN}

La frontera entre Bolivia y Chile es examinada a través de métodos etnográficos para el caso específico de la convergencia de relaciones, movilidad y economías que caracterizan el vínculo entre San Pedro de Atacama y la provincia de Sud-Lípez principalmente. La exposición distingue tres momentos de emergencia del fenómeno. El primero ligado al histórico movimiento de mercancías sobre una base motor animal que ha caracterizado esta zona y que exploramos a partir de la memoria oral de nuestros entrevistados; un segundo momento vinculado al auge minero del azufre a mediados del siglo XX, que desata sus propias lógicas de movilidad, además de la proletarización y monetarización de su economía; y un tercer momento vinculado a la transnacionalización de los flujos migratorios, su intensificación y el desarrollo de nuevas economías migrantes en el marco ya de formaciones globales o globalizantes. La frontera queda así dibujada en su contradictoria y porosa dinámica, para producir y distribuir viejas y nuevas identidades.

Palabras clave: Frontera; Movilidad; Desierto de Atacama; Espacialidad.

* Este trabajo se enmarca en la difusión de resultados de los proyectos Fondecyt Chile 1160963 Espacialidades transfronterizas en el desierto de Atacama, CNRS ANR DS0805 Le savoir mécanique dans les sociétés amérindiennes du Chaco y l'Atacama y CNRS LIA Mines Atacama - Archéologie, histoire et anthropologie des systèmes miniers dans le désert d'Atacama. Quiero agradecer también al programa Chaire des Amériques, del Instituto de las Américas de Rennes, que permitió desarrollar este manuscrito en el marco de una estadía de investigación en la misma ciudad, entre marzo y abril de 2016. Núcleo Milenio Movilidades y Territorios, Iniciativa Milenio, Ministerio de Economía-Chile.

${ }^{1}$ Correo electrónico: agarces@ucn.cl. ORCID iD: <https://orcid.org/0000-0002-4792-6623>.

${ }^{2}$ Correo electrónico: iagonzalez2@uc.cl. ORCID iD: <https://orcid.org/0000-0002-1594-5854>.

${ }^{3}$ Correo electrónico: nicolas.richard@enrs.fr. ORCID iD: <https://orcid.org/0000-0002-2959-3984>.

${ }^{4}$ Correo electrónico: leosonei@gmail.com. ORCID iD: <https://orcid.org/0000-0003-0200-9327>. 


\section{SUMMARY}

The border between Bolivia and Chile is examined using ethnographic methods for the specific case of the convergent social relations, mobility and economies that characterised the relationship between San Pedro de Atacama (Chile) and the province of Sud-Lípez (Bolivia). The paper identifies three moments in the emergence of this phenomenon. The first is related to the historical animal-based movement of goods that has characterised this region, and which we explore though the interviewees' oral memory. The second concerns the mid-twentieth century sulphur-mining boom which unleashed its own mobility rationale, in addition to the proletarianisation and monetarisation of the economy. The third is linked to the transnationalisation of migratory flows, their intensification and the development of emergent migrant economies, in the framework of global or globalising formations. Hence the contradictory and porous dynamics with which the border has been drawn, producing and distributing old and new identities.

Keywords: Border; Mobility; Atacama Desert; Spatiality.

\section{INTRODUCCION}

Las movilidades históricas y la tardía implantación de la frontera nacional entre Chile y Bolivia marcan en la actualidad un escenario difuso para la estructuración de un nuevo espacio de relaciones nacionales y étnicas. Una noción de frontera debe dotar de un carácter dinámico a estos espacios, pues a partir de ella se organiza la comunicación entre los distintos espacios nacionales y en ese sentido distribuye también identidades. En esta línea, el presente artículo intenta examinar la porosidad que han permitido estas fronteras desde el siglo XX en adelante, para concluir en el actual escenario de San Pedro de Atacama como nodo de una circulación migrante fronteriza y transnacional. El material con el que trabajamos proviene del trabajo de campo desarrollado en períodos sucesivos entre los años 2013 y 2015, y se basó en la observación participante y entrevistas en profundidad en localidades a ambos lados de la frontera boliviano-chilena, en particular poblados de la provincia de Sud-Lípez y los municipios de San Pedro de Atacama y Calama en Chile. A continuación, distinguimos formas de la movilidad transfronteriza en estos espacios durante el último siglo, formas porosas de la frontera que en cierto sentido constituyen capas que pueden organizarse cronológicamente, pero que al mismo dan cuenta de la pervivencia de modos de vida y economías que con sus herencias articularon/articulan el espacio de la puna atacameña.

Siguiendo a Kearney (1999: 601 y 2008), en los espacios fronterizos interactúan tres tipos de términos: las fronteras, entendidas como demarcaciones político-territoriales, las identidades cruzadas por las variables de etnia, clase y nacionalidad y, los regímenes, como organismos y entidades oficiales y no oficiales encargadas de trazar y hacer respetar las fronteras. Debemos observar entonces una espacialidad sobre la que desde arriba actúan los distintos Estados-nación instaurando legitimidades y formas de adscripción para individuos y colectivos, mientras que por abajo nos encontramos con los desplazamientos y flujos de los sujetos nacionales e indígenas que con su tránsito re-significan y negocian las clasificaciones en juego. De este modo, más allá de la verificación de categorías estáticas o estatizantes acerca de las pertenencias nacionales o étnicas, interesa su reconstrucción o rearticulación a partir del movimiento y porosidad que caracteriza a estas fronteras nacionales. 
Las fronteras nacionales suponen regímenes, marcaciones que al distinguir a la personas y las mercancías que por ella cruzan, al valorarlas y establecer la legitimidad de determinados flujos en desmedro de otros, cristaliza la actuación de las soberanías nacionales. Las fronteras emergen entonces como un conjunto de dispositivos de seguridad, de higienización (Garcés 2014; Garcés, Moraga y Maureira 2016) que sostienen procesos de apertura y cierre en la distinción de nacionalidades, tipos de mercancía e identidades que dan lugar a una nueva espacialidad transfronteriza.

Para algunos autores, el estudio de las fronteras debiera orientarse al estudio de las relaciones de poder, en y entre naciones y estados, con especial énfasis en las fronteras culturales e identitarias (Donnan y Wilson 1999: 1-2). Lo que se pone en juego entonces es el problema de la soberanía, en el sentido de esa ecuación que presupone una relación isomórfica entre un territorio, unas poblaciones y una soberanía legítima, una extensión del isomorfismo espacio-cultura, que tanto se ha criticado en la antropología los últimos años (Gupta y Ferguson 1992). He aquí los términos de la disputa inaugurada por la trasiego de poblaciones en movimiento junto a mercancías y economías de la frontera. Ahora bien, para efectos analíticos es importante entender también que la frontera incorpora instituciones y procesos, esto es, instituciones que delimitan la soberanía estatal y los derechos de la soberanía individual, mientras que como procesos tienen diferentes funciones: son instrumentos de las policías estatales, constituyen narrativas de la frontera, son indispensables en la construcción de la culturas nacionales, y tienen un importante rol en la reproducción de la nación y el Estado, produciendo discursos y narrativas de identidad (Anderson 1993; Donnan y Wilson 1999: 5). Entonces, el escenario que se nos propone conjunta los límites jurídicos que reúnen y separan estados, los distintos mecanismos de control de las fronteras (que las sostienen) y los espacios variables en que a través de discursos y prácticas se renegocian las identidades nacionales y étnicas.

El conjunto de rigideces y porosidades que caracterizan los espacios fronterizos, adquieren realidad en una frontera nacional como la de Chile y Bolivia, que vino a sancionarse política y jurídicamente por última vez con el tratado de Paz y Amistad firmado 1904, al menos en la perspectiva del estado chileno. El tratado viene a poner término al conflicto bélico iniciado en 1879 y que es conocido actualmente como Guerra del Pacífico o Guerra del Salitre. El tratado significó una importante pérdida territorial para Bolivia, en concreto del antiguo Departamento del Litoral, con la consecuente cercenación de la salida al mar para este último país. A partir de allí, la tensión por el despojo se ha mantenido de modo permanente hasta nuestros días, a veces agudizándose como en el período de las dictaduras militares en los años 70 y 80, a veces latente como en los años anteriores donde se mantuvieron una serie de flujos como veremos. Respecto de esta tensión en la actualidad, baste decir que se encuentra en proceso un litigio entre ambos países ante la Corte Internacional de la Haya, cuyo fallo se espera para 2018 o 2019.

Dicho esto, la investigación de fronteras en la zona que nos ocupa tiene un carácter aún bastante fragmentario e inconexo (Molina 2010). En antropología pueden reconocerse trabajos que detectan cierta dinámica transfronteriza principalmente a partir de economías ganaderas, que por su decaimiento se plantean siempre en términos de aquello que ya fue, de prácticas que quedaron en el pasado de una economía 
ganadera que abasteció la industria del salitre ${ }^{5}$ durante las primeras décadas del siglo XX. Pueden destacarse aquí los trabajos de Sanguinetti y Mariscotti (1958), Bilbao (1974), Cipolletti (1984), Karasik (1984), Rabey et al. (1989), Sanhueza (2001), textos que permiten enlazar en general la puna de Jujuy y el valle de Fiambalá con el Salar de Atacama en su sector meridional, pero también con San Pedro de Atacama y Toconao, al mismo tiempo que, aunque en menor medida, la conexión entre SudLípez con San Pedro de Atacama. Sin embargo, es posible encontrar trabajos que dan cuenta de la pervivencia de esta movilidad transfronteriza o su carácter ya definitivamente contemporáneo en los trabajos de Göbel (1998 y 2002), acerca de las relaciones entre Susques y el Salar de Atacama (en particular Toconao), y el de Imilan (2007), acerca de la movilidad socaireña a Calama, que ya detecta patrones de movilidad contemporáneos con el lado argentino de la frontera.

\section{A. Momento tropero. La Circulación de animales y abastecimiento}

Como primer eje de movilidad nos referimos al intercambio de los habitantes fronterizos del área más austral de Bolivia, hoy en día las provincias de Sud y Nor Lípez con los habitantes circundantes al salar de atacama y del Alto Loa. Nos referimos a lo que Molina denominó "los otros arrieros", una movilidad y sociabilidad al margen de los grandes circuitos de arriería hacendal que abastecieron los enclaves mineros del salitre entre los periodos de 1880 y 1930 (Conti 2003; Molina 2011). En cualquier caso es importante señalar que esta otra arriería descrita por Molina, refiere a territorios (puna y salar de Atacama) ubicados más al sur del espacio que nos convoca en este trabajo. La cuestión aquí es la visibilización de un flujo y de una espacialidad que, por un lado no puede ser reducida al mero abastecimiento de los asentamientos mineros del salitre, y por otro se resiste u opera subversivamente respecto de las demarcaciones fronterizas (limítrofes) que instauraron los estados nacionales a fines del siglo XIX e inicios del XX (Sanhueza 2001).

Como nos relataron habitantes de localidades en Los Lípez existe una extensa red de parentesco con los poblados fronterizos del salar de Atacama y el alto Loa, la cual se ha venido desarrollando por lo menos desde principios del siglo XX. El medio estuvo constituido por los viajes de caravanas, los cuales posibilitaron un intercambio económico y social, que incluía la circulación de mercancías y personas. Nos señalaron que antiguamente muchas localidades no existían como asentamientos permanentes, sino estacionales, donde sus habitantes iban y venían en diversas direcciones, desde ambas vertientes de la cordillera y tanto del norte como del sur. Es por esto que encontramos habitantes que provienen de pueblos que hoy son fronterizos, y que desarrollaron un trasiego constante entre la puna y los valles, guiados por el andar de las caravanas y el pastoreo de llamas. Aquí la "complementariedad de pisos

\footnotetext{
${ }^{5}$ Mezcla de nitrato de sodio y nitrato de potasio que se encuentra naturalmente en amplias zonas desérticas de América del sur, principalmente en Bolivia y Chile. Sus usos se relacionan con la fabricación de ácidos, además de ser un agente oxidante que se usa en agricultura como fertilizante. Tiene otros usos en la medicina y en la fabricación de pólvora, dinamita, y otros explosivos, pirotecnia, vidrios, fósforos, gases, sales de sodio, pigmentos, conservantes de alimentos y esmalte para alfarería.
} 
ecológicos" (Murra 1975) muestra toda su potencia explicativa para dar cuenta de la dispersión y movilidad de estas poblaciones en el territorio.

Conocí San Pedro de Atacama, Río Grande, Caspana. Esas comunidades, son comunidades no son ciudades, entonces a esas comunidades íbamos. ¿Qué llevábamos? Llevábamos tejidos, carne fresca que son las llamas y después llevábamos costales, chulos, guantes con eso para cambiar con esos productos que nos hacían falta. Y allá nosotros cambiábamos, mayormente llevábamos carne de llama. Eso cambiábamos con trigo, con maíz, con trigo molido, para poder traer aquí a nuestras casas (Habitante Quetena Grande, entrevista personal, mar. 2013).

La extensa red de rutas del suroccidente boliviano se empalma en dos vías fronterizas principales (aduanizadas) hacia Chile, una por Hito Cajones (orientada a San Pedro de Atacama) y otra por Ollagüe (orientada a las localidades del Alto Loa y la ciudad de Calama). Dependiendo de los productos a intercambiar y la cercanía a los valles de la vertiente occidentales u oriental de la cordillera se intensificó el intercambio. El flujo era predominante desde los poblados de altura hacia los valles más templados (Mapa 1).

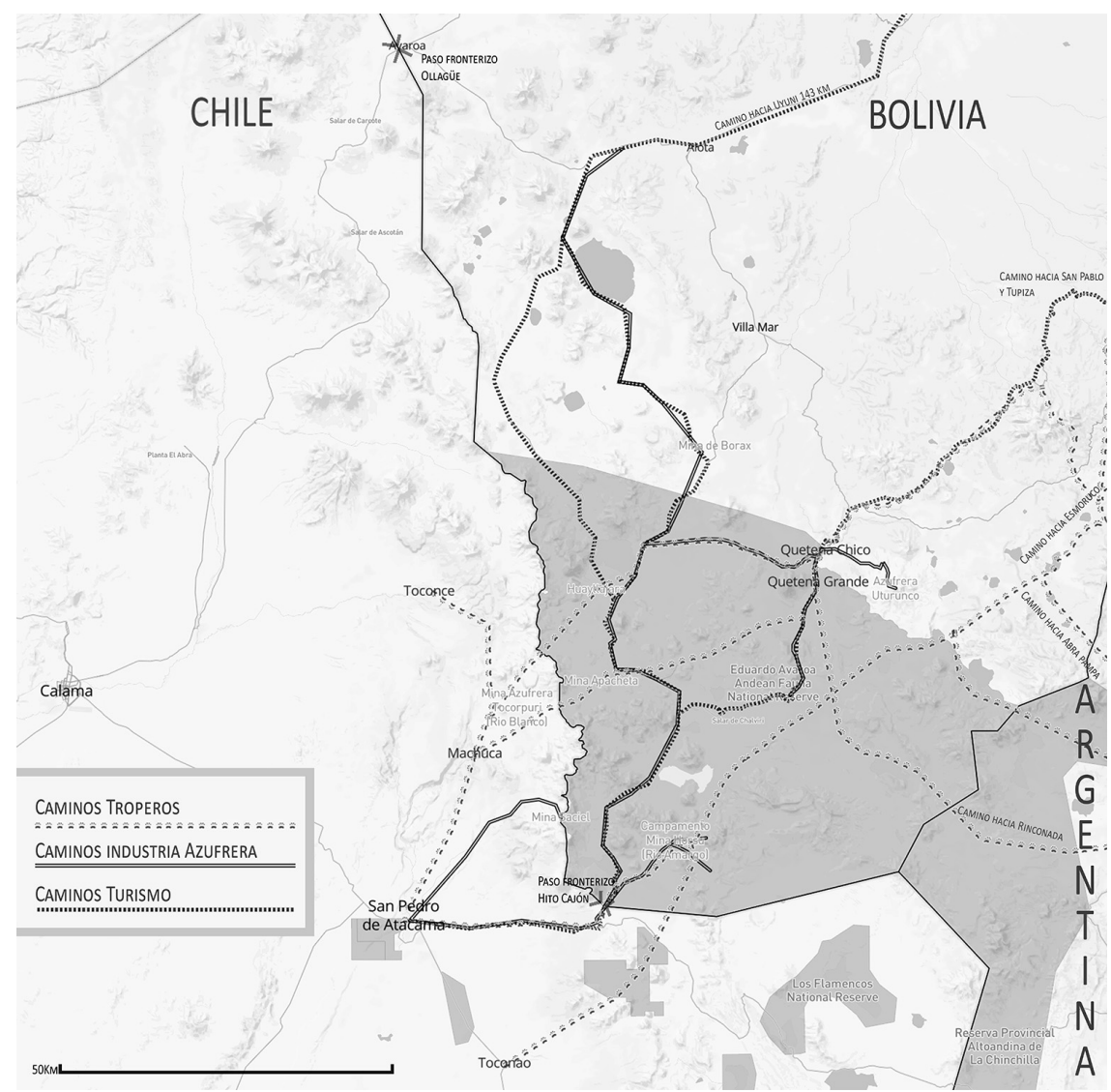

MAPa 1.-Sistema de caminos entre San Pedro de Atacama-Lípez. Fuente: elaboración propia 
Era un poco más lejos. Cuatro a cinco días es. Eso se iba a Cusi Cusi, Rinconada al Toro. Bueno así se llevaba la lana de llama y también se traían los productos que no había aquí. No era cambalache, sino que tú vendes la fibra, cuantos kilos has llevado y te pagan el dinero y te compran con el dinero, eso no es cambalache, ya no, con dinero (Habitante de Quetena chico, entrevista personal, mar. 2013).

El intercambio se constituye sobre la base de economías domésticas y a través del trueque. La monetarización de estos espacios será un proceso lento que se inicia de modo incipiente en la segunda mitad del siglo XX, y estará acompañada de la aparición de mercancías no tradicionales. Los productos más demandados por los pueblos fronterizos de Bolivia a los poblados chilenos eran el chañar ${ }^{6}$, el algarrobo y fruta fresca y deshidratada. También se obtenían alimentos procesados como azúcar y harinas refinadas. Desde el lado argentino se podían obtener harina, azúcar y productos agrícolas, mayormente cereales. Las caravanas venían provistas de productos derivados del ganado de camélidos como charqui (carne seca), pieles, lana, tejidos, confecciones de cuero y en el destino se carneaban algunas llamas para intercambio. En ocasiones también se comerciaba material arqueológico y productos provenientes de Bolivia como la hoja de coca. El desarrollo de la industria de la lana en Argentina, hasta la guerra de las Malvinas, ofrecía un precio atractivo para los pueblos de la puna, los cuales transportaban y vendían en los pueblos fronterizos de Argentina, dinero con el cual accedían a bienes de primera necesidad. Los viajes se realizaban mayormente en verano y coincidiendo con los periodos de esquila y cosecha.

Las tropas se constituían en la mayor parte de los casos por llamas, también se integró el uso de burros que alcanzaron un protagonismo importante en los trayectos de menor distancia. La cantidad de viajes va a depender de los productos que se desee intercambiar, por lo general eran tropas de entre 25 y 60 animales, guiadas por un adulto y un joven, mientras los niños comenzaban a acompañar a sus padres desde temprana edad. Un factor importante en la frecuencia de los viajes responde a la proximidad y requerimientos de productos. Por ejemplo, los habitantes de San Pablo de Esmoruco viajaban a los poblados fronterizos de Chile a buscar fruta, y no lo hacían todas las familias del pueblo ya que por proximidad realizaban mayor intercambio con poblados de Argentina. En cambio, Quetena (Sud Lípez) por su aislamiento con respecto a centros de abastecimiento de Bolivia y Argentina mantuvo itinerarios constantes de intercambio con los poblados fronterizos de Chile por lo que el viaje lo realizaban integrantes de prácticamente todas las unidades familiares, y más de una vez por temporada.

Las rutas troperas contaron con una serie de equipamientos. A lo largo del trayecto hay estaciones de descanso que posibilitan el resguardo del viento, aprovisionamiento de leña y fuentes de agua cercana, además de contar también con señaléticas y espacios rituales como son las apachetas. Estos elementos dan cuenta de rutas altamente estabilizadas para el trasiego de largas distancias. También se daba, pero en menor grado, el flujo desde Chile para realizar intercambios, en búsqueda de carne de llama, huevos de parina $^{7}$ y venta de mercancías.

\footnotetext{
${ }^{6}$ Árbol de corteza verde y amarillenta, con fruto dulce y comestible. De gran relevancia en la zona por sus distintos usos materiales y simbólicos, la etnohistoria de la zona lo ha puesto como una de sus más importantes referencias, destacando el libro Pueblos de Chañar y Algarrobo: los atacamas del siglo XVII (Martínez 1998).
}

7 Tipo de flamenco, de la familia de los Phoenicoparrus. 
anteriormente como no había fronteras las tropas de Chile entraban acá a comprar carne a traer azúcar harina artículos de primera necesidad, entonces venían las tropas de Chile hasta acá, llegaban hasta acá con mulas con burros, de San Pedro salían de Caspana, de Toconao con fruta y en el tiempo bueno eso sí. Y en eso cuando mi papá tenía 17 años conocía acá a mi mamá y él se enamoró de mi mamá y se quedó acá, quedó en Bolivia (Tomás, habitante Quetena Grande, entrevista personal, mar. 2013).

Cuando se bajaba a San Pedro (en los sesenta) no teníamos mucho control, solo carabineros, nos controlaban porque no miraban la tropa, no controlaban, no nos preguntaban qué llevábamos, solo había que hacer una declaración verbal de qué llevábamos y cuántos días queremos entrar y nos daban el permiso (Ángel, habitante de Esmoruco, entrevista personal, may. 2014).

Como vemos, esta articulación transfronteriza se encuentra cimentada en un flujo económico, cultural y simbólico denso, sobre una red de rutas estabilizadas y ampliamente equipadas para el trasiego de tropas caravaneras, rutas previas a la demarcación de las fronteras nacionales. Y como hemos venido señalando, coloca a la movilidad en una relación de dependencia respecto del ciclo minero del salitre, donde el arrieraje soportaba en gran medida el abastecimiento de los asentamientos salitreros. El trasiego transfronterizo tropero hasta avanzado el siglo XX no parecía ser obstaculizado por los regímenes de frontera hacia ambas vertientes, condición que aún parecen conservar los pueblos fronterizos bolivianos con algunas localidades del departamento de Santa Catalina, en la argentina provincia de Jujuy.

\section{B. Industria AZufrera. Periferias Mineras}

El segundo eje está caracterizado por la penetración de la industria minera a mediados del siglo XX en la puna sur andina, tanto en Chile como en Bolivia. Principalmente se trata de la intensificación de la explotación del azufre, industria que articula los primeros caminos carreteros transfronterizos e interregionales del área circumpuneña boliviana hacia Chile, destinado al traslado de mineral a centros de acopio en San Pedro de Atacama, Calama y Uyuni. Esta industria cambió el carácter del trasiego transfronterizo dinamizando circuitos de movilidad laboral y suministros para el abastecimiento de los enclaves mineros, integrando nuevas tecnologías en la movilidad de la puna y reconfigurando las prácticas en torno al abastecimiento e intercambio de los pueblos de la puna.

Ya a principios del siglo XX se van dando las condiciones para la expansión de la industria azufrera en la puna chilena (Sanhueza y Gundermann 2007; González Pizarro 2008) y posteriormente en el sector de Los Lípez en Bolivia. La instalación de enclaves mineros a tan alta altura y en condiciones tan adversas exigió una serie de requerimientos materiales, tecnológicos y de contingente de mano de obra disponible y adaptada a las puna, a lo que pueblos de Los Lípez se acoplaron sin mayor dificultad. Con la tracción animal de la llama y el burro, llareta como combustible, y sus habitantes, que en gran parte del siglo XX se vieron involucrados en algún ámbito de la explotación azufrera, ya sea en la construcción inicial de caminos, campamentos, plantas de refinamiento, aprovisionando, trabajando en esas plantas, en la mina o extrayendo llaretas, entre otras labores. 
Por el 65-68..., cuando comenzó la azufrera, ahí aprovechaban de ir con burro hasta Laguna Verde nomás, hasta la azufrera y ahí los camiones todos los días iban a San Pedro. Ahí se bajaban los camiones (Bernabé, habitante de Quetena Chico, entrevista personal, mar. 2013).

Aquí había llamas, como de por si los machos que decimos nosotros tenían 6 años, 7 años para viajes, exclusivamente para viajes grande. Esas llamas fueron perdiendo, prefirieron entregar la carne a las azufreras y sacar de ahí la mercadería y cualquier cosa hacer. Fue un cambio radical (Tomás, habitante de Quetena Grande, entrevista personal, may. 2014).

La industria azufrera revoluciona el sistema de caminos en la puna, desatando nuevas movilidades e integrando el transporte motorizado (Richard, Moraga y Saavedra 2016) El transporte tradicional de tracción animal se ve parcial y progresivamente reemplazado por el motorizado, mientras la especialización y selección de los animales de carga se pierde. Los tiempos de traslado se acortan y supeditan al ritmo del mineral. Los circuitos de transporte y abastecimiento se diversifican integrando nuevos destinos y adaptando huellas troperas como caminos carreteros, labor realizada para la industria por lo mismos habitantes de Los Lípez. Se trata principalmente de la apertura de caminos para la explotación de llareta y el transporte del mineral a través del tren hacia Calama por el camino a Chiguana y por el paso de Hito Cajón. Todo esto a desmedro de otros caminos que quedaron al margen de los nuevos circuitos de trasiego. Como toda industria en la puna de Atacama, esta rejerarquizó/reorganizó el sistema de caminos y rutas, que se sobreimpuso a los caminos de la economía tropera.

Los caminos carreteros comenzaron cuando yo tenía como 18-20 años. Recién habían, digamos, podrían llegar aquí los carros con algunos productos, más anterior no. Este camino llegaba a una empresa. De laguna Colorada a Uturunco, esa era una empresa y se iba a Uyuni, llegaba por dos partes y otra empresa que conocí era don sin nombre, esa era azufrera también (Habitante de Quetena Grande, entrevista personal, may. 2014).

Es recién con la construcción de los caminos carreteros que los pueblos de Los Lípez ven a Uyuni como destino de aprovisionamiento. Aún así, San Pedro de Atacama se mantiene hasta la rigidización de la frontera en los años 70 como el principal destino. De esta manera, los pueblos de la puna se acoplan a los nuevos circuitos y sus movilidades.

Claro, le vendíamos a la empresa (carne de llama) y rescatábamos un dinerito. Que iba cobrar yo a La Paz, yo era el carnicero, estuve un año y medio de carnicero ahí con contrato e iba a cobrar en La Paz todo mi sueldo de la carne, en el banco mercantil de La Paz, ahí cobraba y ya teníamos dinero (Zacarías, Habitante de Quetena Chico, entrevista personal, mar. 2013).

La penetración del capitalismo en la puna no tan solo se dio por este modelo extractivista, sino también por la monetarización de la puna, dado que previamente eran escasas las instancias de compra-venta. El trabajo asalariado se instaura en la puna y algunas empresas utilizaron pulperías como medio de pago.

Sino que llegaba alguien se posicionaba aquí, yo voy a trabajar y él era el dueño. El dueño te pagaba, a usted te daba una mascadita, después un segundo, después un tercero y después el cuarto ahí con una palita en las huellas ahí nos tenían solamente por tener gente por decir que estaban dando trabajo, pero el sueldo era miserable. Más bien por 
eso te digo que Bernabé me dijo que hemos perdido nuestro tiempo, nuestra juventud en las azufreras, en las llareteras. Muchas gentes se han dado cuenta de esto, hoy en día nuestra juventud ya no puede trabajar así, el azufre lleno en la cara (Tomás, habitante de Quetena Grande, entrevista personal, may. 2014).

La gran mayoría de los entrevistados y con quienes pudimos conversar trabajaron en la explotación del azufre ya sea directamente en la extracción del mineral o en otra labor relacionada con la industria. El trabajo directamente relacionado con la explotación se caracterizaba por una alta rotación, condiciones laborales precarias en un ambiente hostil de trabajo e inseguridad económica. El trabajo en la azufrera no se tradujo necesariamente en acceso a más bienes o a acumulación, manteniéndose el ganado de llamas como un pilar de la economía de la puna, y con mayor fuerza en el apogeo de la explotación minera por la demanda de su carne como alimento.

Era un poquito pesado en la tarde, después de las 12 no puedes comer, tienes pesada la cabeza. Porque ahí están los volcanes, es un volcán activo, entonces con el olor del volcán en las tardes (Macario, habitante de Quetena Chico, entrevista personal, may. 2014).

Los trabajadores se integraban a temprana edad en las labores del azufre y en la mayoría de los relatos nos señalaron que duraban un par de años antes de desplazarse a otra mina, al pastoreo o en búsqueda de trabajo en Chile o Argentina. Así los habitantes de la puna iban rotando de mina en mina muchas veces cruzando la frontera hacia las explotaciones chilenas, dinamizando flujos laborales transfronterizos.

Sin papeles, anteriormente había varios que trabajábamos con Terraza, en el 72 trabajé cuando salí del regimiento, me fui a San Pedro porque estaba acostumbrado a trabajar, ahí en Terraza, chofer del mecánico y ahí robaron un camión un boliviano, ahí lo persiguieron. Mis compañeros eran bolivianos y todos estaban ilegales (Tomás, habitante de Quetena Chico, entrevista personal, may. 2014).

Los circuitos de intercambio y movilidad tradicional se mantuvieron permeables a las nuevas fronteras hasta la década de los 70, período en que las dictaduras en los distintos países reforzaron sus límites fronterizos, favoreciendo el desarrollo de nuevas vías de comunicación y transporte, privilegiando la integración a los mercados globales por sobre la continuidad de los espacios históricamente constituidos. Los habitantes fronterizos de Bolivia conservaron en menor medida sus patrones de movilidad tanto hacia los poblados de Argentina como Chile y se integraron al desarrollo de los centros de abastecimiento boliviano. Muchos de los entrevistados, luego de la militarización de la frontera en los años 70, no volvieron a cruzar hacia Chile. En este escenario la demanda de azufre baja en los 80 acabando con la vigencia de varias explotaciones, para en 1993 cerrar la última mina en la puna boliviana (Reserva Nacional de Fauna Andina Eduardo Avaroa 2003: 16). Para ese entonces se comienza a explotar con mayor fuerza los boratos y emerge un incipiente turismo en la zona que a continuación trataremos.

\section{Bolivianización del flujo en San Pedro de Atacama. El espacio transnacional}

Este tercer momento de marca una serie de quiebres en la presencia boliviana en Chile y en particular en San Pedro de Atacama que constituye el foco de esta explo- 
ración. En este sentido, se observará una movilidad que en principio rompe con los flujos marcados por la contigüidad espacial de las poblaciones, en este caso separadas por la frontera, introduciendo una bolivianidad ya no vinculada históricamente a esta espacialidad, al mismo tiempo que anclada al desarrollo de una economía ya no tropera ni minera, sino de servicios.

Los estudios migratorios han abordado el fenómeno en estos espacios, desde una perspectiva que algunos autores han denominado "obsesión por la comunidad rural" (Gundermann y González 2009: 122), donde se imponen paradigmas de migración campo-ciudad, con la construcción de un perfil migratorio de permanencia en destino, y con el pre-establecimiento de una unívoca dirección del desplazamiento entre origen y destino. Por supuesto también esto está relacionado con una antropología clásica que prefigura otra escala de desplazamiento, aquella que va de lo tradicional a lo moderno. Sin inscribirlos necesariamente en este paradigma, pueden destacarse trabajos pioneros en las migraciones como el de Grebe (1986) en las ciudades de Pozo Almonte e Iquique, y los de González (1996a, 1996b y 1997) acerca de la inserción social y económica de aimaras en contextos urbanos. Sin embargo, la actualidad de los desplazamientos migratorios en el desierto de Atacama escapa a lo que estos trabajos pioneros pudieron aprehender. El contexto de apertura económica, el boom minero desde los 90 a esta parte y el desarrollo de las vías y medios de comunicación entre las fronteras, marcan un fuerte crecimiento de la dinámica migratoria, dibujando la escena necesaria para la construcción de un campo transnacional, o unos circuitos migrantes, que conectan el norte chileno con espacios de Argentina, Perú y Bolivia (Guizardi y Garcés 2013).

A diferencia de lo que ocurre en los territorios centrales de Chile, como hemos visto más arriba, la movilidad en estos espacios presenta una dinámica de intercambios específicas y una profundidad temporal también particular. Es posible encontrar una gran variedad de trabajos que dan cuenta de una movilidad que presenta siglos de antigüedad (Berenguer 1995; Briones, Núñez y Standen 2005; Núñez y Nielsen 2011; Pimentel et al. 2011), señalando rutas y describiendo unas poblaciones en movimiento. Sin embargo, la actualidad del desarrollo de las comunicaciones y los medios de transporte, la dinámica de relaciones entre los estados y el auge minero en el norte de Chile, han permitido la intensificación de las migraciones (sobre todo bolivianas) y de los flujos de mercancías en estos espacios (Garcés y Moraga 2015). Este momento es el que podríamos denominar transnacional en el sentido en que supone a los migrantes la capacidad de establecer y mantener unos campos sociales que cruzan fronteras geográficas, culturales y políticas (Glick, Basch y Blanc-Szanton 1992: ix).

La espacialidad de las fronteras que referimos implica comprender el intercambio más allá de la diferencia y fijación de localidades de origen y destino en que se escenifica un desplazamiento migratorio. Más bien, apuntamos a la configuración de estos espacios como campos sociales transnacionales, esto es, un espacio de relaciones sociales para el trasiego de personas y mercancías, que en este caso comunica diversas localidades, grupos sociales y espacios nacionales (Glick, Basch y BlancSzanton 1992: ix; Portes, Guarnizo y Landolt 1999; Pries 2001). Entender la migración o la movilidad migrante como conformadora de un campo implica entender en ella una articulación de diferentes tipos de capitales (sociales, económicos, simbólicos) a partir de los desplazamientos de individuos y grupos, y que se constituye como 
transnacional al momento de desplegarse más allá o por sobre las fronteras nacionales. La relación con estas últimas es ambigua, dado que siguen operando en la definición de las membresías nacionales de los sujetos y en los mecanismos de control de la movilidad que se efectúa en sus límites.

Nos encontramos entonces una espacialidad fronteriza que da lugar a múltiples modos de nombrar al sujeto que protagoniza una movilidad, en un ambivalente juego de identificaciones. La dinámica conduce a la producción de nuevos regímenes de identidad o de relaciones interétnicas, producción en que las fronteras entre la etnicidad y la nacionalidad se encuentran en proceso de rediseño.

Dicho lo anterior, la migración y movilidad en general en estos espacios fronterizos no puede reducirse en el momento contemporáneo a una pura cuestión de pervivencia o historicidad del contacto transfronterizo. El boom minero de los 90 en adelante, más la constitución de San Pedro de Atacama como uno de los principales polos turísticos de la región circumpuneña y de Chile, han producido un importante crecimiento del pueblo, al tiempo que una notable extensión del mercado laboral sobre todo en los ámbitos de la construcción y los servicios (hotelería, restaurantes y turismo). Esta nueva economía, ha convertido a la zona en un polo migratorio de gran vigencia. Como bien señalamos anteriormente, si lo enfocamos desde un paradigma de la movilidad más que de las migraciones, observaremos que las trayectorias son múltiples, que la linealidad entre origen y destino se relativiza, así como la instalación permanente en destino.

En otros trabajos (Guizardi y Garcés 2013; Garcés, Moraga y Maureira 2016) hemos mostrado cómo la migración contemporánea en estos espacios no está ya ligada únicamente a relaciones preexistentes en el territorio o vinculada a un contacto histórico entre dos o más espacios nacionales, como suele presentarse en la teorías migratorias (Arango 2003). En el caso que nos ocupa, además de tratarse de un territorio que hasta hace un siglo solamente pertenecía a Bolivia, observamos cómo la movilidad no se encuentra actualmente atrapada en las relaciones fronterizas que en el apartado anterior explicamos. En este sentido, lo que vemos en terreno es una diversificación de los lugares de origen de los migrantes, articulando territorios bolivianos y chilenos en los cuales no es pesquisable un vínculo histórico, como el que podría esperarse entre el norte grande chileno y los departamentos bolivianos de Oruro y Potosí por ejemplo. En este sentido, la contigüidad espacial ya no podrá unívocamente caracterizar la movilidad en estos territorios.

El crecimiento de la residencia de extranjeros en San Pedro de Atacama, vinculada al desarrollo turístico del pueblo y alrededores, más el influjo de la economía minera, se articula a través de diferentes vías de llegada. Estas dinámicas han configurado un conjunto de espacios y actividades económicas con presencia migrante en el pueblo, dando lugar también a una particular distribución residencial de la población migrante (Mapa 2). Como puede observarse, las zonas de residencia migrante se extienden radialmente desde el centro, este último es donde se concentra la actividad comercial del pueblo. El centro es conocido como ayllu Conde Duque (en rojo), que irradia la concentración residencial migrante hacia áreas periféricas como población El Carmen, población Licancabur, sector Punta de Diamante, entre otros. 


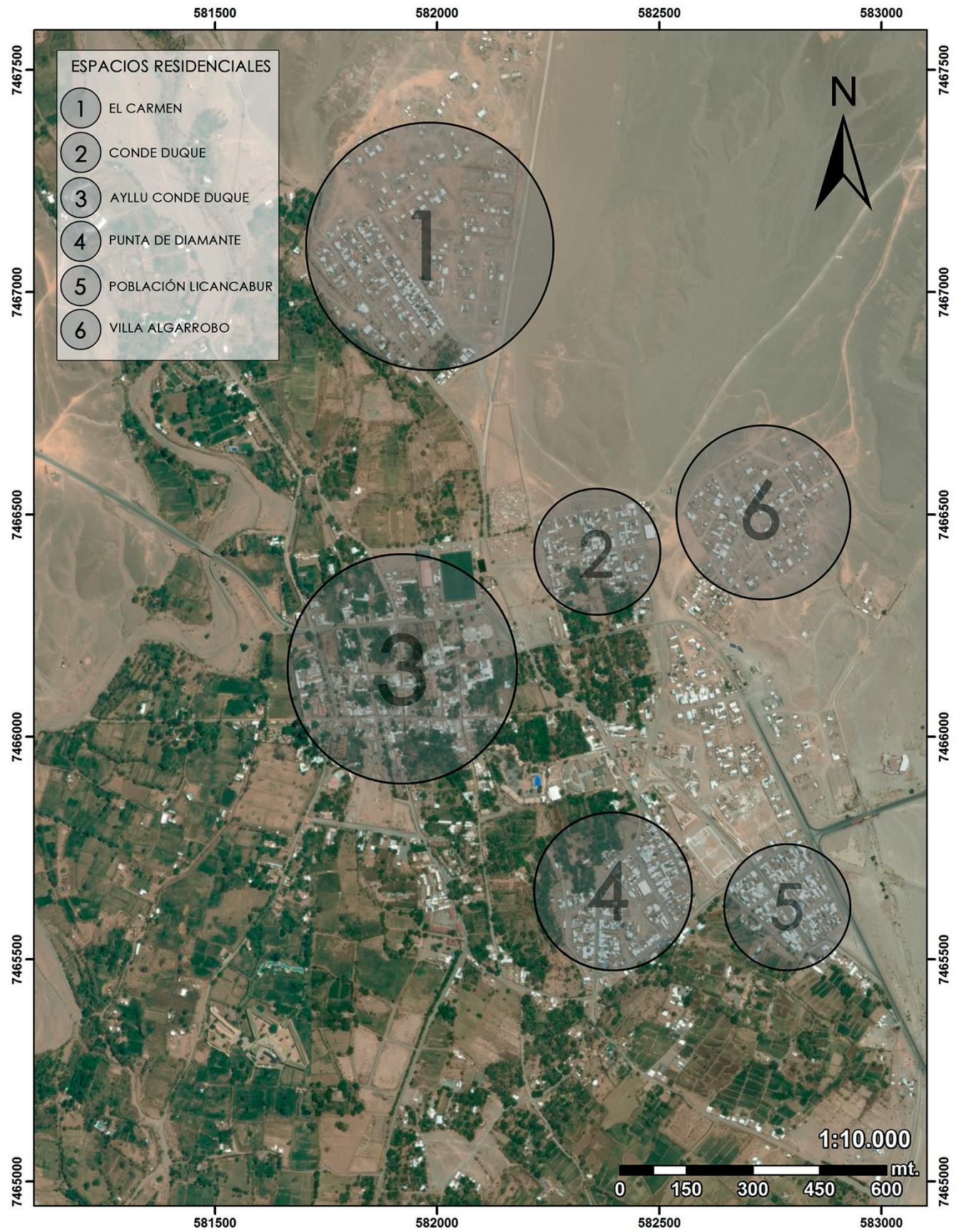

MAPA 2.-Espacios residenciales de los extranjeros en San Pedro de Atacama: 1-El Carmen; 2-Conde Duque; 3-Aillu Conde Duque; 4-Punta de Diamante; 5-Población Licancabur; 6-Villa Algarrobo. Fuente: elaboración propia 
Estas poblaciones surgen en su mayoría a partir de comités de allegados o tomas de terreno por parte de las nuevas familias atacameñas provenientes de pueblos al sur del salar de Atacama. Particularmente, la población Licancabur se originó a comienzos de los años noventa producto del traslado de pobladores de otras zonas aledañas al pueblo (como Camar y Talabre) hacia San Pedro de Atacama. A partir de ahí comienza la inserción de familias bolivianas que marcan un primer momento de instalación extranjera en el barrio, que es seguido a partir del 2000 por la llegada de extranjeros peruanos que se insertan en el mercado de trabajo local.

Los tipos de residencia en los que habitan tanto peruanos como bolivianos se manifiestan diversos. En algunos casos, los pobladores locales adaptan espacios de vivienda (pequeñas piezas o cabañas) que no siempre son adecuados en cuanto a necesidades básicas (p. ej. agua potable y luz). Estas irregularidades precisamente se hacen extensibles a la ausencia de un contrato de arriendo en relación a los supuestos bajos costos del mismo. Algunos trabajos vinculados al rubro de la construcción, que en general absorben mayor cantidad de mano de obra, propician precisamente la precariedad de las condiciones laborales, en donde los lugares de habitación tienden a estar constreñidos a pequeños espacios (hacinamiento). Esta situación marca una continuidad con la precarizada forma que adquiere la vivienda de los migrantes en otras regiones del país (Mujica 2004). No obstante, se dan otras situaciones en donde una solidaridad del dueño del negocio, facilita el acomodo a un habitar más adecuado. Caso especial es el contexto que describen algunos hoteles en San Pedro de Atacama, en donde estas empresas habilitan habitaciones en el mismo lugar para sus trabajadores. En este caso, los extranjeros peruanos y bolivianos (generalmente en labores de mucama o cocinería) se adscriben a este tipo de condiciones facilitadoras, aunque se restringen en algunos casos las libertades personales y facilitan jornadas y horarios de trabajo extendidos e irregulares.

Suelen ser variados los motivos que gatillan el desplazamiento de una población tanto dentro como fuera de un país. Sin embargo, es habitual que dentro de las causas más comunes sea la búsqueda de una mejor situación económica. Nuevas oportunidades laborales, deudas financieras y fracasos económicos, son a veces relatos frecuentes de muchos extranjeros. Sin embargo, dejar la explicación del desplazamiento exclusivamente en estos términos coloca la opción de migrar en un marco de decisiones individuales, maximizadoras de una racional ecuación de costo-beneficio. Las teorías migratorias han avanzado bastante en la perspectiva de superar los enfoques economicistas, apuntando hacia perspectivas articulacionistas, centradas en el papel de las redes y en la conformación de ciertos capitales sociales al interior de las comunidades migrantes (Kearney 1986; Arango 2003).

En este marco, si bien la cuestión económica suele ser una respuesta recurrente, cabe preguntarse por qué la búsqueda de un mejoramiento económico activa, y de qué modo, un flujo migratorio. Asumimos que las causas son diversas y que a su vez poseen matices, no obstante el siguiente relato puede dar luces en cuanto a cómo se construyen ciertas disposiciones que posibilitan las migraciones desde el núcleo familiar:

Nací en Potosí, Bolivia, en Tambillos. Somos 11 hermanos y todos se fueron. Tengo en otros países otros hermanos, otras hermanas y dentro de Bolivia también. Actualmente tengo tres hermanos chicos, y ahora aquí en San Pedro les ayudo enviando dinero. En Bolivia 
llegué hasta quinto básico y luego me fui con mi hermano a Santa Cruz, y a los 18 años partí a La Paz y conseguí trabajo como empleada. Luego me vine a Chile a trabajar porque mis amigos me contaron que había trabajo en San Pedro (Mujer boliviana, 24 años, entrevista personal, may. 2015).

La búsqueda de nuevos horizontes distintos al lugar de origen no es casual, en tanto, tiene un componente que se configura a partir de redes familiares y antecedentes que corroboran que la migración es efectiva a partir de la experiencia de otros. En el caso de esta migrante boliviana, el itinerario que se dibuja implica un largo recorrido que incluye a Perú, desde el lugar de origen ubicado en el departamento de Potosí, pasando luego a Santa Cruz de la Sierra y La Paz, y desde allí por Perú hacia Chile pasando por las grandes ciudades del norte hasta llegar a San Pedro de Atacama. Cabe resaltar que la decisión sobre movilizarse a un territorio diferente, no siempre involucra ventajas respecto a una integración laboral más cómoda, como lo sería teniendo una red social facilitadora, como lo describe la misma persona:

En Argentina tengo algunos tíos y tías, pero no me gusta ir allá. También tengo a mi hermano en Brasil. Saliendo de acá (San Pedro de Atacama) me quiero ir a Brasil a ver cómo es todo. Acá en San Pedro de Atacama llegué sola y me gusta, porque tengo amigos y la mayoría de la gente me conoce, cuando voy caminando la gente me saluda (Mujer boliviana, 24 años, entrevista personal, may. 2015).

Otras personas indican que las causas que motivan la migración no tienen que ver directamente con el mejoramiento de su situación económica, sino que existen otras variables, a veces personales como, por ejemplo, las características de los lugares que han venido componiendo sus itinerarios migratorios.

Primero viví en Uyuni, luego me fui a Potosí a estudiar y después me fui a Santa Cruz. Como es una ciudad tan grande, mucho tráfico, y me vine por lo mismo, por cambiar el ambiente. Acá en San Pedro me iba a quedar como tres o cuatro meses, pero ya llevo como 4 años. Estuve también en Argentina un año trabajando, y luego me vine para acá. San Pedro me gusta porque es tranquilo, tú puedes andar en bicicleta, a pie, entonces tú en una ciudad grande no puedes andar así, más que todo por eso me vine acá (Mujer boliviana, 40 años, entrevista personal, may. 2015).

Esta misma persona da cuenta que existen ciertos elementos que indican una predisposición al migrar, o bien una tradición familiar a partir de categorías internas que estarían gatillando el desplazamiento del grupo:

Mis papas son de Sucre y por el trabajo nos fuimos a Uyuni, compramos casa y nos quedamos ahí. Cuando yo estaba en Santa Cruz trabajé tres años como profesora, luego me salí de ahí y estuve un año sin trabajo. Como mis papas trabajaban en San Cristóbal (Potosí), me dijeron que había trabajo, entonces yo me fui con mi esposo (Mujer boliviana, 40 años, entrevista personal, may. 2015).

En ambas historias es posible notar que el migrar nace de estructuras internas a partir de las experiencias del grupo familiar: padres, tíos y hermanos, de forma que el núcleo familiar ha construido nociones que predisponen estas dinámicas. El desplazarse de un lugar a otro, se percibe como algo común y necesario. A pesar de que estas historias personales tienden a superponer el aspecto económico como una de las causas del tránsito, no deja de ser importante la articulación que permite 
visualizar una red social migrante. Esta se caracteriza por la información que facilita la experiencia en aspectos laborales, aquellos elementos económicos del lugar de destino, del flujo de recursos, interconexión de redes parentales, entre otros (Martínez Veiga 1997).

Ahora bien, en los itinerarios de los extranjeros podemos ver emerger de modo recurrente el paso por Argentina, no solo en tránsito hacia localidades chilenas como San Pedro de Atacama, sino como lugares en que también se asentaron y trabajaron. Esto nos remite a la formación de un circuito migrante (Rouse 1988) entre Chile, Bolivia y Argentina (Guizardi y Garcés 2013). Hasta los años noventa Argentina constituyó uno de los primeros destinos migratorios para peruanos y bolivianos, cuestión que a partir de la última década se ha visto desacelerada. La razón de ello puede encontrarse en factores estructurales relacionados con los ciclos de la economía argentina por un lado, y el potencial atractor del crecimiento económico en el norte chileno amparado en su impulso minero ${ }^{8}$. El circuito al que apuntamos se asienta en el acervo de conocimientos y capitales sociales que las comunidades migrantes van acumulando y consolidando en el tiempo, respecto de rutas migratorias y lugares de asentamiento. El carácter autónomo y autosostenido del fenómeno migratorio una vez iniciado (Massey et al. 1993) adquiere concreción en la formación de este circuito. La co-presencia de bolivianos y peruanos con la población local de San Pedro de Atacama, hace emerger una serie de fricciones. Se construye una imagen del inmigrante como competidor laboral en donde son comunes los discursos que tienden a negativizar y a generalizar a la población extranjera, cuestión que se expresa en sentencias tales como "vienen a quitarnos el trabajo", y que se acompañan de otras como "la gente prefiere a peruanos y bolivianos, porque como vienen indocumentados trabajan más horas y por menos plata". A su vez, emergen también cuestiones de orden histórico y/o político, como lo relata el caso de una persona proveniente de Bolivia que trabaja como mucama en un hotel:

Los pasajeros te miran y te preguntan, ¿̇e dónde eres?, ¿eres chilena? A veces te confunden con los atacameños de acá, porque la gente atacameña son igual así morenitos... y te miran así. Y si dices que eres de Bolivia lo primero que dicen es, los bolivianos están aquí porque les quitamos el mar, nos odian porque les quitamos el mar. Los que son así, la gran mayoría son de Santiago, los que más te discriminan, son los más racistas, porque piensan que cuando ellos vienen acá, uno es su nana, entonces tiene que hacerles las cosas (Mujer boliviana, 40 años, entrevista personal, may. 2015).

La discriminación que describimos se da también en los espacios comerciales (p. ej. los puestos de artesanías), en donde además de la fricción existente con la población local, se ven expuestos al contacto de turistas frecuentemente chilenos, quienes hacen notar su diferencia en rasgos fenotípicos, al acento, el color de piel, etc. Sin embargo, no todas las actividades laborales en que se insertan los extranjeros suponen necesariamente un contacto con la población o con turistas. En general, puede observarse una segmentación del mercado de trabajo por sexos, donde las mujeres

\footnotetext{
${ }^{8}$ Si bien la migración boliviana a la Argentina tiene una profundidad anterior y puede pesquisarse desde el siglo XIX, de acuerdo al último censo (2001) la población boliviana en Argentina alcanzaba las 233464 personas, mientras el consulado boliviano la estimaba 947503 (Sassone 2009)
} 
suelen trabajar en los puestos comerciales de artesanías, servicios domésticos en hotelería (p. ej. mucama) y cocinería, mientras los hombres realizan comúnmente trabajos en la construcción. Particularmente en el caso boliviano, las mujeres en San Pedro de Atacama describen un panorama laboral de desempleo en sus lugares de origen, cuestión que no sería tal en el caso de los hombres. A consecuencia de ello, se han observado casos en que las mujeres bolivianas incursionan en áreas laborales que son típicas del género masculino, como la construcción y el transporte?

La escena contemporánea que dibujamos, dislocada de la contigüidad espacial que caracterizó la movilidad histórica que describimos anteriormente, y constitutiva de la mayor parte del flujo migratorio en las localidades chilenas, acoge en su interior o permite la reemergencia de los lazos familiares que articularon los movimientos transfronterizos en el siglo XX, ahora en la forma de apropiaciones de la economía turística en ebullición.

La industria turística comienza a desarrollarse de manera incipiente en la puna boliviana en los años 80, previamente en el año 1975 se crea la Reserva Natural Eduardo Abaroa (que comienza a operar en 1995). Hoy en día se perfila como uno de los principales atractivos turísticos de Bolivia. A finales de los años 90 el flujo turístico por el paso Hito Cajones aumenta de manera considerable, dando lugar a la constitución de la ruta turística Uyuni-San Pedro de Atacama. Hoy en día transitan diariamente más de 80 turistas solo de entrada a Chile por Hito Cajones. Turistas con requerimientos de alimentación, alojamiento, guías y transporte que son provistos en parte importante por los habitantes de Los Lípez, es decir, las redes sociales que organizaron la movilidad y el espacio en la puna, se recrean ahora en las construcción de alojamientos y alimentación en los distintos puntos de una ruta que ahora comienza a constituirse como aquella que une a San Pedro de Atacama con Uyuni, más allá de Los Lípez.

Ya avanzada la década del 90 con el creciente dinamismo de la industria turística en San Pedro de Atacama ${ }^{10}$ y la consolidación del circuito que lo une con Uyuni, surge un nuevo patrón migratorio de carácter fronterizo. Las trayectorias de Melina e Iber, residentes en Chile y provenientes de los pueblos fronterizos bolivianos de Villa Mar y Soniquera, son ejemplos de las nuevas temporalidades migratorias, que a ratos se confunden con la migración boliviana del interior y que invisibiliza esta continuidad tradicional, étnica y fronteriza.

La infancia de Melina en Villa Mar, como la de la gran mayoría de los habitantes de los pueblos fronterizos de altura aquí mencionados, la vivió en torno a la dinámica de la estancia y el pueblo, entre las temporadas de escuela y vacaciones en que se iba a cuidar del ganado. Ya con mayor edad los jóvenes, al igual que Melina, migran temporalmente en vacaciones a trabajar a poblados urbanos, como Uyuni, a realizar

${ }^{9}$ Los extranjeros bolivianos, por pertenecer a un país asociado al Mercosur, suelen instalarse en San Pedro de Atacama de modo más ventajoso que otros colectivos extranjeros, dada la visa temporaria a la que pueden acceder por dicha membrecía. En el caso peruano la situación es más compleja dado que como cualquier trabajador extranjero debe contar con una visa de trabajo para poder acceder en forma regular al mercado laboral.

${ }^{10}$ San Pedro de Atacama recibió 141969 visitantes el 2015, quienes realizaron 375894 pernoctaciones, marcando una tasa de ocupabilidad de habitaciones disponibles de un $64 \%$, la más alta del país. De los 926000 turistas que ingresaron a Chile en 2015 y que en total generaron divisas por US\$ 536,3 millones, el 15 \% visitó San Pedro de Atacama (Sernatur 2016). 
labores de servicio doméstico principalmente. En el año 2001, terminada la secundaria a los 17 años, decide ir a San Pedro de Atacama.

Mucha gente siempre venía así por temporada, mas ante mi padre había venido como me contaba a San Pedro, él siempre venía a hacer trueque, entonces él me contaba que en San Pedro es mejor, entonces dije yo voy ir a San Pedro. Igual yo tenía un medio hermano que antes había venido acá, medio hermano de parte de papá, entonces él me dijo, si acá en San Pedro se gana bien pero igual hay que ser responsable, honesto y todas esas cosas. Y me vine sola sin tener familia acá ni nada, después conocí por ejemplo como estamos en un pueblo tan chico, pero no los conocía su familia de mi abuela (Melina, entrevista personal, mayo 2015).

Como se da cuenta no utiliza una red de parentesco que la integre en primera instancia a San Pedro de Atacama, pero tiene la experiencia previa de sus familiares que la motivan. Ingresa a Chile por el paso de Hito Cajón de manera ilegal y en San Pedro de Atacama comienza a trabajar en la realización de labores domésticas en casas particulares, en hoteles y en los nichos laborales que se integran o insertan los bolivianos. Con el transcurso de los años regulariza su situación legal en Chile, conoce parientes que residen en San Pedro y adquiere experiencia en el rubro del turismo. En el año 2012 abre su propia agencia de viajes y en el 2013 realiza circuitos transfronterizos con agencias operadas por familiares en Uyuni, Bolivia.

Por su parte, Iber (26 años, oriundo de Quetena), a los 9 o 10 años de edad cruza la frontera por primera vez hacia San Pedro de Atacama en la temporada de vacaciones para visitar a sus familiares, pero es después de terminar sus estudios de secundaria en Uyuni que su estadía pasa a ser más prolongada. Anteriormente ya había viajado su hermana mayor a los 15 años a vivir con un familiar chileno en San Pedro de Atacama. Iber comienza atendiendo un café, posteriormente viaja a Calama y toma estudios técnicos al igual que su hermano, estudios que no completa ya que abre su negocio de turismo en San Pedro de Atacama.

La espacialidad que construye la actividad turística de Iber a través de su agencia turística ponen manifiesto la apropiación de un territorio a partir de unos vínculos familiares dispersos, donde precisamente esa dispersión es rentabilizada en el negocio. En este caso, tenemos que en asociación con su hermano Iber dispone de hostales y albergues en Quetena Grande y Quetena Chico (Hostal de Huallajara), su agencia de turismo en San Pedro de Atacama, otra agencia en Uyuni en asociación con sus hermano Porfidio e Idónea (ambos originarios de Quetena), los servicios de alojamiento que un primo le presta en Laguna Colorada, y el acceso a reccorridos por Uturuncu y puerto Chuvica. A este despliegue y rendimiento del territorio podrían sumarse los vínculos desplegados por sus hermanas María y Lourdes con sus agencias en San Pedro de Atacama.

En San Pedro de Atacama hay actualmente más de 20 agencias de turismo que pertenecen a extranjeros bolivianos provenientes de pueblos fronterizos de Nor y Sud Lípez. En el caso de la agencia de Iber y Melina, como en la mayoría de estas agencias, los circuitos turísticos que atraviesan la frontera son administrados en el marco de las redes familiares y negocios establecidos en Uyuni y San Pedro de Atacama, así como a largo de los caminos que les conectan $^{11}$. Se recuperan y/o sostienen de

${ }^{11}$ Utilizando como nodo del circuito los alojamientos administrados localmente por el poblado de Quetena Chico. 
este modo las redes que ancladas al territorio, en la contigüidad espacial de sus dispersos lugares de origen y destino, configurando una espacialidad a ratos invisible, que a veces se sirve y a veces ignora aquella que recientemente vienen a marcar las fronteras nacionales.

\section{CONCLUSIONES}

Como se ha expuesto, observamos tres momentos que organizan la movilidad y construyen una espacialidad transfronteriza en la puna atacameña. Vistos longitudinalmente desde el siglo pasado, estos espacios actualizan circuitos, migraciones, movilidades, mercancías. Pasando del intercambio en el marco de una economía familiar, a un régimen extractivista que les proletarizaba, para hoy en día adentrarse en una economía basada en los sectores de la construcción, la hotelería y la prestación de servicios turísticos. La frontera que separa (más intensamente a partir de fines de los 70), muestra aún su porosidad para servir a economías que se organizan precisamente sobre el acto de transitarlas, de atravesarlas. Se trata de movilidades engarzadas en patrones históricos de movilidad, determinando un flujo bidireccional transfronterizo y protagonizado centralmente por unidades familiares, y otras que responde en mayor medida a los patrones migratorios actuales de la migración a Chile, aquella en que se ven diversificados los espacios de origen en Bolivia, y que descansa menos en la redes sociales previas para su inserción en destino.

Esta superposición de movilidades, que inscribimos en un momento transnacional de los flujos migratorios internacionales, viene a complejizar el marco tradicional de relaciones interétnicas que monopolizan el discurso de la identidad en estos territorios. Desde comienzos de los 90 con los gobiernos democráticos en Chile, quizás desde las reformas político-administrativas de la dictadura militar en los 80 , se observa una emergencia de las demandas étnicas en Chile que coincide con un incremento de los procesos de autoidentificación étnica, y que en términos políticos ha conducido a la formación de, por ejemplo, municipios andinos como espacios políticos en construcción (Gundermann 2003: 68). Esta municipalización de lo étnico supone que no tratamos necesariamente con las estructuras tradicionales del mundo andino, atacameño o aimara, sino que estamos ante la emergencia de nuevas formas, lógicas y representaciones de lo étnico, donde los mediadores políticos locales son la expresión de los nuevos liderazgos y formas de representación (ibid: 71). Lo anterior es asimilable a lo planteado por algunos autores, en cuanto al surgimiento dentro de la nueva etnopolítica atacameña, de una burocracia indígena compuesta por líderes y dirigentes que conducen la política local, mediando/traduciendo entre las demandas indígenas y la acción de la política pública desde el Estado (Boccara y Bolados 2008; Morales 2014).

Dispositivos que discursivamente producen lo étnico y lo nacional. Etnopolíticas cuya temporalidad y complejidad queda raptada en el aparato que inaugura una moderna ley indígena, o en las construcciones de una alteridad imaginada desde San Pedro de Atacama y/o sus márgenes chilenos, collas o bolivianos, como si la política (esa que organiza jerarquías y espacios) pudiera reducirse espacial/nacionalmente a la jurisdiccionalidad de una ley, a la fuerza de una chilenización a base de escuelas, 
iglesia y servicio militar. Es el Norte Grande de Chile y su presunción de membresías y lealtades, que otorga demasiada primacía a la agencia del Estado-nación en la definición de los límites del espacio (fronteras), y que se suspende temporalmente a la espera de la feliz ecuación que parece producirse entre una institucionalidad estatal y una escena específica de liderazgo y poder político.

Se configura entonces un código básico de interrelaciones, que parte de la base de habilitar unos actores legítimos. Pero donde la dinámica de aquello que se intenta nombrar posee una estructura en la que emergen nuevos otros que la atraviesan con suma facilidad y frecuencia, apeados ya no sólo en las relaciones sociales construidas históricamente (Oruro y Potosí), sino en nuevos tipos de redes que les conectan con espacios en Bolivia sin antecedentes de movilidad hacia Chile, como lo muestran los casos que hemos expuesto. He aquí el influjo del boom minero en el norte de Chile y la expansión de economías de servicios como el turismo por ejemplo. Se desata entonces una nueva organización de estas relaciones interétnicas, donde tanto lo chileno, lo étnico y lo extranjero adquieren una nueva densidad y heterogeneidad interna, y donde la bolivianidad, siempre en situación subordinada respecto de lo atacameño y chileno, empieza a emerger en nuevas formas vinculadas a un nuevo empresariado turístico que trabaja a partir de su dominio de la condición fronteriza, de sus porosidades y rigideces, y del capital social construido en estos territorios durante décadas.

\section{BIBLIOGRAFÍA CITADA}

Anderson, Benedict. 1993. Comunidades Imaginadas. Reflexiones sobre el origen y la difusión del nacionalismo. México: Fondo de Cultura Económica.

Arango, Joaquín. 2003. "La explicación teórica de las Migraciones: luz y Sombras". Migración y Desarrollo 1. Disponible en: <http://www.redalyc.org/articulo.oa?id=66000102>. Fecha de acceso: 5 jun. 2017.

Berenguer, José. 1995. "Impacto del caravaneo prehispánico tardío en Santa Bárbara, Alto Loa" en Actas del XIII Congreso Nacional de Arqueología Chilena, tomo 1, 9: 185-202. Antofagasta/Santiago de Chile: Instituto de Investigaciones Antropológicas/Universidad de Antofagasta/Sociedad Chilena de Arqueología. Disponible en: <https://www.researchgate.net/publication/284682656_Impacto_del_ caravaneo_prehispanico_tardio_en_Santa_Barbara_Alto_Loa_En_Actas_del_XIII_Congreso_Nacional_ de_Arqueologia_Chilena_Hombre_y_Desierto_Tomo_I_9_185-202_Antofagasta_1995>. Fecha de acceso: 5 may. 2017.

Bilbao, Santiago. 1974. "Un análisis de las formas económicas en la cultura folk de la quebrada de Humahuaca y su área de influencia", en Cuadernos de CICSO: 1-39. Serie Estudios, 13. Buenos Aires: Centro de Investigaciones en Ciencias Sociales.

Boccara, Guillaume y Paola Bolados. 2008. "Dominar a través de la participación. El neoindigenismo en el Chile de la posdictadura". Memoria Americana. Cuadernos de Etnobistoria 16(2): 167-196. Buenos Aires: Universidad de Buenos Aires.

Briones, Luis, Lautaro Núñez y Vivien Standen. 2005. "Geoglifos y tráfico prehispánico de caravanas de llamas en el desierto de Atacama (Norte de Chile)". Chungara 27(2): 195-223. doi: <http:// dx.doi.org/10.4067/S0717-73562005000200007>.

Cipolletti, María Susana. 1984. "Llamas y mulas, trueque y venta: El testimonio de un arriero puneño". Revista Andina 4: 513-538.

Conti, Viviana. 2003. "El norte argentino y Atacama. Flujos mercantiles, producción y mercados en el siglo XIX", en Alejandro Benedetti (comp.), Puna de Atacama. Sociedad, economía y frontera: 21-52. Córdoba: Alción. 
Donnan, Hastings y Thomas Wilson. 1999. Borders: Frontiers of Identity, Nation and State. Oxford/ Nueva York: Berg Publishers.

Garcés, Alejandro. 2014. "Contra el espacio público: criminalización e higienización de la migración peruana en Santiago de Chile». EURE. Revista De Estudios Urbano Regionales 40(121): 141-162. doi: <http://dx.doi.org/10.4067/S0250-71612014000300007>.

Garcés, Alejandro y Jorge Moraga. 2015. "Reconfiguraciones de la economía y sociedad aymara en la frontera de Chile y Bolivia: el caso Colchane-Pisigan, en Tanja Camal-Cheluja, Juan Carlos Arriaga-Rodríguez y Eric Cardín, Fronteras y dinámicas transfronterizas en América Latina: 305332. Chetumal: Universidad de Quintan Roo.

Garcés, Alejandro, Jorge Moraga y Marcelo Maureira. 2016. "Tres movilidades para una ruta: espacio, comercio y transnacionalidad boliviana en Tarapacá". Estudios Atacameños. Arqueología y antropología surandinas 53: 205-220. doi: <http://dx.doi.org/10.4067/S0718-10432016005000010>.

Glick Schiller, Nina, Linda Basch y Cristina Blanc-Szanton. 1992. "Towards a Definition of Transnationalism. Introductory Remarks and Research Questiones", en Nina Glick Schiller, Linda Basch y Cristina Blanc-Szanton (eds.), Towards a Transnational Perspective of Migration. Race, Class, Ethnicity and Nationalism Reconsidered: ix-xiv. Nueva York: Annals of the New York Academy of Sciences.

Göbel, Bárbara. 1998. "Salir de viaje. Producción pastoril e intercambio económico en el noroeste argentino", en Sabine Dedenbach-Salazar, Carmen Arellano, Eva Köning y Heiko Prümers (eds.), 50 años de estudios americanistas en la Universidad de Bonn. Nuevas contribuciones a la arqueología, etnohistoria, etnolingüistica y etnografía de las Américas: 867-891. Estudios Americanistas de Bonn, 30. Markt Schwaben: Verlag Anton Saurwein.

Göbel, Barbara. 2002. "La arquitectura del pastoreo: Uso del espacio y sistema de asentamientos en la Puna de Atacama (Susques)". Estudios Atacaeños 23: 53-76. doi: <http://dx.doi.org/10.4067/ S0718-10432002002300005>.

González, Héctor. 1996a. Características de la migración campo-ciudad entre los aymaras del norte de Chile. Serie Documentos de Trabajo. Arica: Corporación Norte Grande.

González, Héctor. 1996b. Los migrantes aymaras en la ciudad: acceso a educación, vivienda y salud. Serie Documentos de Trabajo. Arica: Corporación Norte Grande.

González, Héctor. 1997. "La inserción económica de los migrantes aymara en la ciudad: el trabajo como empresa familiar y la reproducción cultural. Actas Segundo Congreso Chileno de Antropología: 315-324. Santiago: Colegio de Antropólogos de Chile.

González Pizarro, José. 2008. «La emigración boliviana en la precordillera de la región de Antofagasta, 19101930. Redes sociales y estudios de caso". Revista de Ciencias Sociales Universidad Arturo Prat 21: 61-85.

Grebe, María Ester. 1986. «Migración, identidad y cultura aymara: puntos de vista del actor». Chungara. Revista de Antropología Chilena 16-17: 205-223.

Guizardi, Menara y Alejandro Garcés. 2013. "Circuitos migrantes. Itinerarios y formación de redes migratorias entre Perú, Bolivia, Chile y Argentina en el norte chileno". Papeles de Población 48: 65-110. Disponible en: <http://www.scielo.org.mx/scielo.php?script=sci_arttext\&pid=S1405$74252013000400005 \& \operatorname{lng}=e s \& n r m=i s o \& t \operatorname{lng}=e s>$. Fecha de acceso: 5 jun. 2007.

Gundermann, Hans 2003. "Sociedades indígenas, municipio y etnicidad. La transformación de los espacios políticos locales andinos en Chilen. Revista de Estudios Atacameños 25: 55-77. doi: <http:/ /dx.doi.org/10.4067/S0718-10432003002500004>.

Gundermann, Hans y Héctor González. 2009. «Sociedades indígenas y conocimiento antropológico. Aymaras y atacameños de los siglos XIX y XX. Chungará, Revista de Antropología Chilena 41(1): 113-164. doi: <http://dx.doi.org/10.4067/S0717-73562009000100008>.

Gupta, Akhil y James Ferguson. 1992. "Beyond "Culture": Space, Identity, and the Politics of Differencen. Cultural Anthropology 7(1): 6-23. doi: <https://doi.org/10.1525/can.1992.7.1.02a00020>.

Imilan, Walter. 2007. "Socaireños en movimiento. Atacameños y Calama". Estudios Atacameños: Arqueologia y Antropología Surandinas 33: 105-23. doi: <http://dx.doi.org/10.4067/S0718-10432007000100007>.

Karasik, Gabriela. 1984. Intercambio tradicional en la puna jujeña. Tesis de Licenciatura. Universidad de Buenos Aires.

Kearney, Michael. 1986. "From the Invisible Hand to the Invisible Feet: Anthropological studies of Migration and Development. Annual Reviews of Anthropology 15: 331-361. doi: <https://doi.org/ 10.1146/annurev.an.15.100186.001555>. 
Kearney, Michael. 1999. "The Local and the Global: The Anthropology of Globalization and Transnationalism", en Steven Vertovec y Robin Cohen (eds.), Migration, diasporas and transnationalism: 520-538. Cheltenham: Edward Elgar.

Kearney, Michael. 2008. "La doble misión de las fronteras como clasificadoras y como filtros de valor", en Laura Velasco (ed.), Migración, fronteras e identidades étnicas transnacionales: 79-116. Tijuana/ México: El Colegio de la Frontera Norte/Miguel Ángel Porrúa.

Martínez, José Luis. 1998. Pueblos del chañar y el algarrobo: los atacamas en el siglo XVII. Santiago: Dirección de Bibliotecas, Archivos y Museos Centro de Investigaciones Diego Barros Arana, DIBAM.

Martínez Veiga, Ubaldo 1997. La integración social de los inmigrantes extranjeros en España. Madrid: Trotta.

Massey, Douglas, Joaquín Arango, Graem Hugo, Ali Kouaouci, Adela Pellegrino y J. Edward Taylor. 1993. "Theories of International Migration: a Review and Appraisal". Population and Development 19(3): 431-466.

Molina, Raúl. 2010. Collas y Atacameños en la Puna y el Desierto de Atacama y el Valle de Fiambalá: sus relaciones transfronterizas. Tesis doctoral. Universidad Católica del Norte.

Molina, Raúl. 2011. "Los otros arrieros de los valles, la puna y el desierto de Atacama". Chungará (Arica) 43(2): 177-87. doi: <https://doi.org/10.4067/S0717-73562011000200002>.

Morales, Héctor. 2014. "Génesis, Formación y Desarrollo del movimiento atacameño (Norte de Chile)". Estudios Atacameños 49: 111-128. doi: <http://dx.doi.org/10.4067/S0718-10432014000300007>.

Mujica, José. 2004. El desafio de la solidaridad: Condiciones de vida y de trabajo de los peruanos migrantes en Chile. Serie Documentos de Trabajo, 178. Lima: Organización Internacional del Trabajo.

Murra, John. 1975. "El control vertical de un máximo de pisos ecológicos en la economía de las sociedades andinas", en John Murra, Fomaciones económicas y políticas andinas: 59-115. Lima: Instituto de Estudios Peruanos.

Núñez, Lautaro y Axel Nielsen. 2011. "Caminante, sí hay camino: Reflexiones sobre el tráfico sur andino", en Lautaro Núnez y Axel Nielsen (eds.), En Ruta. Arqueología, Historia y Etnografía del tráfico sur andino: 11-41. Santiago: Encuentro.

Pimentel, Gonzalo, Charles Rees, Patricio de Souza y Lorena Arancibia. 2011. "Viajeros costeros y caravaneros. Dos estrategias de movilidad en el Período Formativo del desierto de Atacama, Chile", en Lautaro Núnez y Axel Nielsen (eds.), En Ruta. Arqueología, Historia y Etnografía del tráfico sur andino: 43-81. Santiago: Encuentro.

Portes, Alejandro, Luis Guarnizo y Patricia Landolt. 1999. "The Study of Transnationalism: Pitfalls and Promise of an Emergent Research Field". Ethnic and Racial Studies 22(2): 217-237.

Pries, Ludger. 2001. "The approach of transnational social spaces. Responding to new configuration of social and spatial", en Ludger Pries (ed.), New Transnational Social Spaces. International Migration and Transnational Companies in the Early Twenty-first Century. Londres: Routledge.

Rabey, Mario, Margarita Ozcoidi, David González y Mario Sánchez Proaño. 1989. "Legalidad e ilegalidad del coqueo en Argentina", en Instituto Interamericano (ed.), La Coca...Tradición, Rito, Identidad: 35-78. México: Instituto Indigenista Interamericano.

Reserva Nacional de Fauna Andina Eduardo Avaroa. 2003. Programa de protección. Serie Documentos de trabajo, 1. La Paz: Trópico.

Richard, Nicolás, Jorge Moraga y Adrián Saavedra. 2016. «El camión en la Puna de Atacama (19301980): mecánica, espacio y saberes en torno a un objeto técnico liminal". Estudios Atacameños 52: 177-199. doi: <http://dx.doi.org/10.4067/S0718-10432016005000005>.

Rouse, Roger. 1988. Mexican Migration to the United States: Family Relations in the Development of a Transnational Migrant Circuit. Tesis Doctoral. Universidad de Standford.

Sanguinetti, Amalia y Ana M. Mariscotti. 1958. "Notas para el estudio de la cultura de la Puna". Runa 9(1-2): 195-206.

Sanhueza, Cecilia. 2001. "Las Poblaciones de la puna de Atacama y su relación con los estados Nacionales. Una lectura desde el archivo". Revista de Historia Indígena 5: 55-82. Disponible en: <https://revistas.uchile.cl/index.php/RHI/article/view/39968/41537>.

Sanhueza, Cecilia y Hans Gundermann. 2007. "Estado, expansión capitalista y sujetos sociales en Atacama (1879-1928)». Estudios Atacameños: Arqueología y Antropología Surandinas 34: 113-136. doi: <http://dx.doi.org/10.4067/S0718-10432007000200007>. 
Sassone, Susana. 2009. "Breve geografía histórica de la migración boliviana en la Argentina", en María Virginia Ameztoy (org.), Buenos Aires Boliviana. Migración, construcciones identitarias y memoria: 389-402. Temas de Patrimonio Cultural n. ${ }^{\circ}$ 24. Buenos Aires: Gobierno de la Ciudad de Buenos Aires/Ministerio de Cultura de Argentina.

Sernatur [Servicio Nacional de Turismo]. 2016. Cuadro Estadístico EAT por Destino serie 2014-2015. Disponible en: <http://www.sernatur.cl/wp-content/uploads/2016/11/Cuadros-estadisticos-EAT-pordestino_Serie-2014-2015_version-final.xlsx>. Fecha de consulta: 10 jul. 2018.

Fecha de recepción: 30 de junio de 2017

Fecha de aceptación: 27 de abril de 2018 